\title{
Portal de Periódicos da CAPES: um misto de solução financeira e inovação*
}

\author{
Cynthia Harumi Watanabe Correa \\ Universidade Estadual de Londrina \\ Isabel Merlo Crespo \\ PUC-RS \\ Ida Regina Chitto Stumpf \\ Universidade Federal do Rio Grande do Sul \\ Sonia Elisa Caregnato \\ Universidade Federal do Rio Grande do Sul
}

\section{RESUMO}

O Portal de Periódicos da CAPES (Coordenação de Aperfeiçoamento de Pessoal de Nível Superior do Ministério da Educação) é uma biblioteca digital de acesso à informação científica e tecnológica produzida em âmbito mundial. Atende instituições públicas e privadas de ensino, pesquisa, planejamento e desenvolvimento, para as quais disponibiliza um acervo de periódicos em texto integral, bases de dados, patentes, monografias e outros recursos. O estudo delineia o histórico do Portal a partir do relato de pessoas diretamente envolvidas com o projeto e com as ações que o antecederam. As entrevistas foram complementadas com a consulta a documentos institucionais. Descreve-se o panorama inicial a partir das experiências do PAAP/CAPES (Programa de Apoio à Aquisição de Periódicos) e do ProBE/FAPESP (Programa Biblioteca Eletrônica da Fundação de Amparo à Pesquisa do Estado de São Paulo), bem como as tentativas de solução dos problemas de acesso às publicaçôes periódicas internacionais, que levaram à criação do Portal.

\footnotetext{
* As autoras agradecem as sugestões recebidas dos pareceristas anônimos que melhoraram a versão original deste trabalho.
} 
Relatam-se as dificuldades iniciais de negociação com as editoras e as restrições ao uso do meio eletrônico pela comunidade acadêmica. Mostra-se como foram superadas as dificuldades de aceitação e de infra-estrutura, para que a implantação do Portal tivesse êxito. Conclui-se que o Portal é uma ferramenta de caráter democrático e irreversível de acesso à informação científica e tecnológica, contribuindo para melhorar a qualidade da ciência brasileira.

Palavras-Chave | Comunicação Científica; Periódicos Eletrônicos; Portal de Periódicos da CAPES; Brasil

Códigos JEL | O32; O33

\begin{abstract}
The Portal de Periódicos da CAPES (a public foundation attached to the Brazilian Ministry of Education) is a digital library for scientific and technical information access. The Portal provides educational, research, planning and development agencies from both public and private sectors in Brazil with access to collections of fulltext journals, databases, patents, monographs and other sources. This paper restores the Portal history through accounts from people directly involved in the project and in its preceding activities. Interview data was complemented by an analysis of institutional documentation. It describes the context that led to the launching of the Portal, which was characterized by two previous government experiences of journals acquisition and the search for a solution to the problem of accessing international journals. It discusses the initial difficulties related to dealing with publishers and part of the academic community who opposed to the electronic media. It shows how infra-structure and acceptance barriers were overcome. It concludes that the Portal is a democratic and irreversible means of accessing scientific and technical information which is improving the quality of Brazilian science.
\end{abstract}

KEYWORDS | Scholarly Communication; Electronic Journals; Portal de Periódicos da CAPES; Brazil

JEL-CODES I O32; O33 


\section{Introdução}

Desde a segunda metade do século XVII, quando as primeiras revistas científicas passaram a existir, até o presente milênio, os padrões de comunicação entre os pesquisadores foram muito alterados. A variedade de canais ampliouse, abrigando de relatórios técnico-científicos e anais de congresso a mensagens eletrônicas e objetos digitais; os hábitos de recuperação e uso da informação, incluindo os processos de leitura, foram modificados; a Internet e tecnologias relacionadas vieram permitir um intenso fluxo comunicacional que ultrapassa fronteiras geográficas de modo instantâneo. Ainda assim, o artigo de periódico continua sendo o principal meio de comunicação na ciência, graças à legitimidade e credibilidade alcançadas mediante o sistema de avaliação por pares e a garantia da divulgação dos desenvolvimentos científicos recentes.

A fim de permanecer como protagonistas da comunicação científica, as próprias revistas sofreram grandes transformaçōes. Além de suas características físicas, também seus processos de distribuição e comercialização tornaram-se mais sofisticados.

Nessa evolução, os anos 1990 marcam o ápice daquilo que veio a ser conhecido mundialmente como a "crise dos periódicos", ou seja, a incapacidade de as bibliotecas manterem as assinaturas das principais revistas científicas nas respectivas áreas, como resultado da escalada dos preços, impulsionada pelos editores comerciais que passaram a publicá-las e distribuí-las. Desde então, modelos alternativos de publicação científica expandiram-se e, aos poucos, as instituições foram adaptando-se a eles e moldando novas iniciativas.

Imersa nesse contexto, a ciência brasileira não ficou imune às transformações. A criação do Portal de Periódicos da CAPES em novembro de 2000 é um marco dessa metamorfose, pois se constitui em uma biblioteca digital de informação científico-tecnológica atualizada e de qualidade, produzida em âmbito mundial, em textos completos. Hoje, mais de 180 instituições são beneficiadas com o projeto mantido pelo governo federal via Coordenação de Aperfeiçoamento de Pessoal de Nível Superior do Ministério da Educação (CAPES/ MEC). O projeto abrange todas as áreas do conhecimento, com mais de 11 mil títulos de periódicos científicos, aproximadamente cem bases de dados com resumos, informações sobre patentes, monografias e outros recursos. 
O Portal representa a evolução de um modelo baseado no uso de documentos impressos, que atendia a um número restrito de instituições e indivíduos, para um modelo eletrônico que ampliou e democratizou o acesso à informação científica, favorecendo tanto os pesquisadores de grandes centros quanto os de universidades distantes. Ele constituiu-se em uma iniciativa determinante para a inclusão da comunidade científica e acadêmica brasileira no processo de comunicação científica internacional, proporcionando acesso on-line às pesquisas científicas realizadas no mundo e, conseqüentemente, oferecendo insumos para a produção científica e tecnológica nacional. Sua utilização, segundo registros divulgados nas estatísticas, chegou a aproximadamente 15 milhões de artigos e 32 milhões de consultas a bases referenciais em 2006.

Consciente do papel do Portal de Periódicos da CAPES para o avanço da ciência brasileira, associado à carência de relatos acerca da concepção do projeto, o Grupo de Pesquisa em Informação, Tecnologias e Práticas Sociais do Programa de Pós-Graduação em Comunicação e Informação da Universidade Federal do Rio Grande do Sul (UFRGS) procurou mapear o histórico do Portal ao longo dos seis anos de sua criação, recuperando o contexto de seu surgimento e os fatos que determinaram sua implementação e continuidade. As informaçōes foram coletadas por meio de entrevistas realizadas com seis das pessoas envolvidas no planejamento, implantação e desenvolvimento do projeto, selecionadas pelo seu destaque, assim como pela indicação das que as antecederam. Por limitação de recursos, não foi possível entrevistar todos os participantes mencionados. Algumas manifestações foram transcritas literalmente, enquanto outras, comuns aos entrevistados, foram incorporadas ao texto, sem identificação. Dados complementares foram obtidos em documentos institucionais, referenciados no final.

O primeiro a ser entrevistado foi o presidente da CAPES na época de criação do Portal, professor Abílio Afonso Baeta Neves; em seguida, foram entrevistados o então diretor de Programas da CAPES, professor Luiz Valcov Loureiro; o presidente da CAPES a partir de fevereiro de 2004, professor Jorge Almeida Guimarães; o coordenador geral de Cooperação e Intercâmbio da CAPES, que intermediou as discussões com a Rede Nacional de Ensino e Pesquisa (RNP), professor Tuiskon Dick; a responsável pela Coordenação de Acesso à Informação Científica e Tecnológica (CAC) da CAPES, Elenara Chaves 
Elder de Almeida; e a coordenadora do Programa Biblioteca Eletrônica da Fundação de Amparo à Pesquisa do Estado de São Paulo (ProBE/FAPESP) de 1999 a 2002, Rosaly Fávero Krzyzanowski. As entrevistas foram realizadas em Porto Alegre, São Paulo e Brasília.

\section{0 cenário}

"O projeto do Portal foi um misto de solução imposta pela necessidade, mas, ao mesmo tempo, foi a solução que se precisava encontrar, se levarmos em consideração o tamanho do Brasil e o modo como as coisas são feitas no país. O Brasil realmente se adapta a soluçôes que envolvem a formação de grandes redes de compartilhamento."

Com essa convicção e visão de futuro, o idealizador do Portal, o professor Abílio Baeta Neves, define em poucas linhas uma história que começou em 1995. À época, a CAPES já tinha como preocupação central o fato de que a provisão dos meios de informação científica para as universidades públicas, isto é, a capacidade dessas instituiçōes de terem acesso às revistas científicas, estava cada vez mais difícil de ser garantida.

Em 1990, o MEC criou o Programa Brasileiro de Apoio a Bibliotecas por meio da Secretaria de Educação Superior (PROBIB-SESu). Em 1994, entrou em vigor um programa de periódicos baseado em uma ação conjunta entre CAPES, Financiadora de Estudos e Projetos (FINEP), Conselho Nacional de Desenvolvimento Científico e Tecnológico (CNPq) e SESu/MEC, contemplando algumas bibliotecas universitárias. Essas quatro agências dividiam os encargos de financiamento da aquisição de revistas impressas para as universidades do sistema público federal, incluindo parcialmente as instituições públicas paulistas, que recebiam recursos adicionais do estado de São Paulo, seja por meio da FAPESP ou do orçamento das próprias universidades. A partir de 1996, o programa passou a contar, exclusivamente, com o apoio da CAPES. Ainda em 1994, é criado o Programa de Apoio à Aquisição de Periódicos (PAAP), visando assegurar o acesso à produção científica e tecnológica internacional pela comunidade acadêmica brasileira envolvida nas atividades de pós-graduação e de pesquisa. O Programa partia da premissa de que a qualidade 
da produção científica, tecnológica, cultural e artística brasileira estaria relacionada às possibilidades de se consultar a informação publicada em revistas.

Em 1997, a aquisição de periódicos foi centralizada pela CAPES para atender 264 bibliotecas de Instituiçôes de Ensino Superior (IES) a um custo de 21 milhões de dólares por ano. No auge desse programa, era assinado um total de 8 mil títulos, distribuídos pelo sistema, ou seja, nenhuma instituição tinha acesso a 8 mil títulos simultaneamente. Tratava-se, portanto, de um grupo seleto de universidades beneficiadas de forma direta, cabendo às demais o acesso por meio da Comutação Bibliográfica (COMUT). No processo de distribuição de periódicos, a instituição pública que recebia o maior número de assinaturas era a Universidade Federal do Rio de Janeiro (UFRJ), seguida pela Universidade Federal de Minas Gerais (UFMG) e pela UFRGS. A diferença na distribuição entre essas três já era significativa: a UFRJ recebia aproximadamente mil títulos, as outras duas recebiam algo entre 150 e 180 títulos, enquanto as demais recebiam um número ainda menor.

Apesar dos investimentos realizados nos últimos anos, o programa começou a mostrar-se inviável em decorrência de vários fatores: não atendia de forma plena e satisfatória às demandas das IES, nem em relação ao número de instituições envolvidas nem ao de assinaturas; só adquiria periódicos impressos; e a centralização das licitações e das aquisiçôes ocasionava muitos atrasos. Para completar, houve a redução das disponibilidades orçamentárias, em 1998, agravada pelo aumento do dólar, quando o orçamento destinado ao PAAP foi drasticamente reduzido. Essa crise produziu um cenário muito negativo em todos os setores da CAPES, havendo pela primeira vez cortes nas bolsas financiadas pela agência (INFOCAPES, 2002).

A situação exigia uma solução imediata e eficaz, isso porque, segundo o professor Abílio Baeta Neves, o acesso à informação científica estava muito precário, havendo, ainda, a legítima pressão de outras instituições públicas que estavam literalmente fora do programa, como as do Norte e do Nordeste. Para participar, era preciso investir recursos próprios da instituição, mas, como o orçamento das universidades era oscilante, sendo por vezes reduzido, tornava-se difícil garantir a continuidade da participação. Foi quando a CAPES começou a buscar alternativas que permitissem um acesso mais abrangente quanto ao número de instituições e à quantidade de informações científicas. 
A primeira idéia nessa direção foi a dos centros de referência regionais, que seriam depositários de coleções de periódicos a partir de algumas universidades que já tivessem um acervo significativo (INFOCAPES, 2002). A proposta foi inspirada em experiências européias e tinha o professor Tuiskon Dick como entusiasta. $\mathrm{O}$ estudo inicial verificou a estrutura existente nas bibliotecas brasileiras para a organização desses centros pelo país. De acordo com o projeto, algumas bibliotecas selecionadas por grandes áreas de conhecimento, ou uma divisão conjunta por área e região, ficariam responsáveis pelo maior acervo de revistas naquela área e, ao mesmo tempo, pela disseminação do seu conteúdo por meio do COMUT.

Entretanto, mesmo a idéia dos centros em universidades que contassem com infra-estrutura adequada para fazer uma transferência eletrônica de informação era difícil de ser efetivada na prática. O professor Abílio Baeta Neves visitou algumas universidades na Europa (por exemplo, na Alemanha), onde havia bibliotecas de referência que funcionavam durante 24 horas por dia, com bolsistas escaneando textos e enviando-os via rede. Nesses lugares, o texto digitalizado era transferido ao usuário, mas não era armazenado para uso posterior, sendo apagado em um ou dois dias devido a questóes de direito autoral. Por esses fatores, a experiência não poderia ser adotada por um organismo vinculado ao governo brasileiro. No entanto, o projeto dos centros chegou a ser elaborado e buscaram-se recursos para implementá-lo, mesmo sabendo-se que era de difícil execução e que haveria uma série de disputas entre as instituições para definir quais seriam as bibliotecas de referência.

$\mathrm{Na}$ época, muito pouco era pensado em termos de tecnologias da informação e comunicação, como Internet, porque a conexão viabilizada pela RNP era extremamente baixa, segundo o professor Luiz Valcov Loureiro. Paralelamente a isso, o estado de São Paulo já estava dando os primeiros passos na comunicação científica eletrônica, com o ProBE/FAPESP, coordenado pela bibliotecária Rosaly Fávero Krzyzanowski, que se constitui na primeira experiência de disseminação eletrônica no Brasil. O projeto iniciou em 1999 com 606 títulos de periódicos eletrônicos da Editora Elsevier, que eram acessados através de um servidor localizado na FAPESP.

O ProBE era financiado pela FAPESP e considerado um avanço para a época. Iniciou com um consórcio de cinco universidades públicas de São Paulo 
e o Centro Latino-Americano e do Caribe de Informação em Ciências da Saúde (BIREME), chegando posteriormente a incluir mais 32 instituições de ensino e pesquisa e 3 fundações do estado de São Paulo. O sistema funcionava da seguinte forma: a fundação adquiria a licença de acesso às revistas eletrônicas assinadas em papel pelas instituições partícipes do consórcio e, pelo contrato assinado com as editoras Elsevier Science e Academic Press, recebia essas coleçōes em CD-ROM, armazenando-as em um servidor local e assim garantindo a perpetuidade de uso da coleção em sistema on-line, acessado diretamente através da rede ANSP (Academic Network of São Paulo) pelas instituições consorciadas. No caso dessas duas editoras, não havia uma conexão direta com elas; de qualquer forma, ganhava-se tempo, porque os CDs eram atualizados constantemente e em menos tempo do que o necessário para se renovar a coleção em papel. Mesmo com as limitações na quantidade de editoras e títulos, o estado de São Paulo passou a ter acesso a um número de periódicos muito superior ao de outros estados brasileiros, principalmente porque eliminou as duplicações existentes entre as instituições e pôde assinar outros títulos de igual valor ofertados pelas mesmas editoras.

\section{Portal de Periódicos da CAPES: solução em meio à crise}

"O ponto de referência para qualquer mudança de cenário é o problema existente." Com base nesse pressuposto, tanto o presidente da CAPES quanto o diretor de Programas prenunciavam a impossibilidade de manter a aquisição de periódicos em papel devido ao seu valor extremamente elevado. Além disso, não imaginavam que a proposta dos centros de referência regionais pudesse ser menos onerosa. Nem mesmo a experiência pioneira do ProBE, em São Paulo, poderia nacionalizar-se, pois exigiria uma infra-estrutura de tecnologia ainda ausente na época, como o acesso rápido à Internet. As próprias universidades tinham reservas quanto à troca da aquisição em papel pelo suporte eletrônico.

No entanto, com a crise orçamentária que atingia o Governo Federal desde 1998 e com a desvalorização do real, o valor de 50 a 60 milhões de reais destinado ao programa de periódicos, equivalente a cerca de 20 a 22 milhões de dólares, foi reduzido para 9,9 milhões de dólares (INFOCAPES, 2002). No ano seguinte, conforme relata o professor Luiz Valcov Loureiro, a instituição 
dispôs de menos da metade dos recursos para manter o programa de periódicos impressos. Além de não avançar, houve um retrocesso, que acabou sendo importante porque mostrou que o passo deveria ser mais ousado, segundo o então presidente da CAPES. A crise trouxe duas conseqüências para o programa: em primeiro lugar, bloqueou as iniciativas que a CAPES estava planejando, uma vez que necessitaria prever um orçamento crescente com relação ao patamar anterior; segundo, acirrou a disputa entre as instituições que tinham uma grande demanda por informação científica. Mesmo que a situação financeira se normalizasse, o PAAP era um programa desigual em relação ao número de instituições beneficiadas e de títulos assinados.

Assim, a CAPES começou a investir em um novo projeto, baseando-se na iniciativa do ProBE/FAPESP, e simultaneamente passou a dedicar-se à RNP, espelhando-se em experiências internacionais de acesso on-line aos textos integrais. Contudo, para realizar-se processo similar no Brasil, era imprescindível a instalação de uma rede mais veloz. Em outubro de 1999, foi criado o Programa Interministerial de Implantação e Manutenção da Rede Nacional de Ensino e Pesquisa, que previa investimentos conjuntos dos ministérios da Ciência e Tecnologia e da Educação, num total de R \$ 215 milhões, com o objetivo de financiar a implantação e manutenção de uma rede Internet acadêmica avançada, mais conhecida como RNP2 (RNP, 2006). Entre os membros do Comitê Gestor da RNP, estava o professor Tuiskon Dick, representante da CAPES, defensor do aumento de velocidade da rede para tornar viável a possível assinatura de revistas eletrônicas.

Os contatos iniciais com as editoras foram estabelecidos com o auxílio da bibliotecária Rosaly Fávero Krzyzanowski, que já detinha um conhecimento prévio de contratos assinados para o ProBE/FAPESP. Os primeiros contratos que o Portal de Periódicos da CAPES assinou foram com a Elsevier e com a Academic Press, que permitiram a disponibilização de 1.300 títulos, e, ao final de 2000 , a coleção totalizava aproximadamente 1.800 periódicos com textos completos e cerca de 14 bases de dados de resumos. Por exigência da Elsevier, foram realizados testes de acesso em algumas instituições, entre elas, a UFRGS, a Universidade Federal de Pelotas (UFPel), a UFMG e a Universidade Federal do Pará (UFPA), o que demonstrou, entre outros problemas, que a lentidão da rede tornava impossível baixar textos com ilustrações. 
A partir daí, alguns avanços ocorreram, e a redução do tempo de transmissão de dados permitiu viabilizar o projeto do Portal. Aliado a isso, o programa interministerial de gestão da RNP entrou em operação em maio de 2000, propiciando uma infra-estrutura adequada para a nova rede acadêmica. No ano seguinte, a velocidade da conexão para o exterior passou de 16 para $155 \mathrm{Mbps}$. Isso possibilitou migrar do modelo em papel para o novo modelo eletrônico de acesso à informação científica. Em paralelo, iniciou-se uma recuperação do orçamento na CAPES. No entanto, as expectativas das IES eram de que se voltasse ao antigo programa de assinaturas em papel. Nesse sentido, quando a CAPES começou a discutir o projeto do Portal de Periódicos, a primeira reação foi muito negativa e a proposta foi enfaticamente rejeitada.

Para esclarecer a comunidade, foram promovidas diversas reuniōes com reitores, com membros da Academia Brasileira de Ciências (ABC) e da Sociedade Brasileira para o Progresso da Ciência (SBPC). Com exceção da SBPC, cuja direção era favorável à proposta, a academia posicionou-se majoritariamente contra ela. Segundo o professor Abílio Baeta Neves,

"os acadêmicos tinham muito medo de não poder pegar a revista e lê-la em casa, como também, diziam eles, circular na biblioteca era importante. Questionavam, ainda, a segurança da informação e diziam que ficaríamos nas mãos das editoras que, caso resolvessem acabar com a pesquisa nacional, poderiam bloquear o acesso em meio eletrônico".

Eram argumentos de ordem política, afetiva e institucional contrários à mudança. $\mathrm{O}$ professor mencionou uma reunião com os reitores das universidades federais, na sede da Associação Nacional dos Dirigentes das Instituiçôes Federais de Ensino Superior (ANDIFES), em Brasília, em que um dos participantes reclamou que sua instituição só teria acesso a 1.300 títulos, esquecendo-se de que, pelo programa antigo de assinatura em papel, aquela universidade não recebia nenhuma revista.

Por outro lado, o incentivo de muitas associações acadêmicas e sociedades científicas, como a ANDIFES, a Comissão Brasileira de Bibliotecas Universitárias (CBBU) e a SBPC, e de pesquisadores que defendiam o projeto foi essencial para que se avançasse na direção do suporte eletrônico. Entre os defensores, figurava o professor Jorge Almeida Guimarães, que assumiu a 
presidência da CAPES em fevereiro de 2004, em substituição ao professor Marcel Bursztyn, presidente da instituição de agosto de 2003 a fevereiro de 2004, período em que o Portal teve um grande incremento.

No entanto, em decorrência da pressão e da resistência por parte da comunidade científica, o lançamento do Portal de Periódicos foi retardado até que se pudesse contar com um razoável apoio. De qualquer modo, era evidente que o projeto traria uma série de vantagens, dado o aumento do número de títulos disponíveis e tendo-se em conta que os problemas de acesso e de velocidade da rede estavam relativamente solucionados.

$\mathrm{O}$ aspecto inovador da proposta da CAPES é que pela primeira vez seria possível realizar uma experiência que envolveria imediatamente todas as universidades federais. Vale ressaltar que as instituições paulistas partícipes do ProBE, que possuíam os requisitos da CAPES para participação no Portal, foram neste integradas a partir de 2001. Assim, em 2002, por decisão da FAPESP, o ProBE foi suspenso após as instituiçōes paulistas serem absorvidas pelo Portal, evitando duplicação de esforços e de recursos financeiros pelas duas agências de fomento. $\mathrm{O}$ apoio da comunidade acadêmica e científica de São Paulo era fundamental para assegurar o sucesso do projeto, uma vez que o estado gerava mais de $50 \%$ da pesquisa nacional e, com isso, dobrava o número de consultas ao Portal, explicou o professor Luiz Valcov Loureiro. Logo em seguida, o programa foi ampliado, e as instituições de ensino privadas que possuíam programas de pós-graduação em nível de doutorado com nota igual ou superior a cinco também receberam acesso.

Sem dúvida, havia um deficit de títulos, principalmente se fossem comparados os 1.800 de acesso on-line com os 8 mil adquiridos pelo programa de assinatura em papel, mesmo considerando que nesse montante havia inúmeros títulos duplicados. Essa situação obrigou a CAPES, temporariamente, a investir no Portal e a continuar financiando algumas assinaturas em papel, mesmo sabendo que a manutenção dos dois modelos seria inviável. "As instituições reagiram, mas o ganho era não só do número de instituiçôes que passariam a ter acesso, de 25 para cerca de 80 , mas de democratização do acesso à informação científica, pois se tratava de 80 que tinham acesso a mais de mil títulos", relatou o professor Abílio Baeta Neves. "No programa anterior, das 25 universidades participantes, apenas a UFRJ tinha acesso a mil 
títulos, enquanto outras recebiam 20, cem ou 150, e algumas tinham acesso às assinaturas de apenas 8,10 ou 12 revistas", disse ele.

Por esse viés, o impacto trazido pelo Portal foi instantâneo. Apesar de ter sido inaugurado oficialmente em novembro de 2000 com demonstrações sobre as possibilidades de uso do sistema, só entrou em funcionamento de fato em janeiro de 2001. Já ao longo do primeiro ano, o número de títulos subiu para cerca de 2 mil e, no final de 2002, chegou a quase 3 mil. Foi um processo crescente em que as condições de negociação também foram melhorando, tanto que a cláusula inserida no primeiro contrato da Elsevier, exigindo da CAPES a manutenção das assinaturas em papel, foi posteriormente suprimida.

A questão financeira era outra crítica comum no início, comentou ainda o professor, pois as pessoas temiam que o gasto com esse empreendimento fosse muito elevado. Os críticos não percebiam que colocar o material em meio eletrônico se tratava de uma tendência mundial das editoras. Com a saída das três agências financiadoras da aquisição de periódicos em papel, a CAPES era a única responsável pela assinatura das revistas, que eram distribuídas de forma desigual entre um número restrito de instituições. Com a iniciativa do Portal de Periódicos, cinco anos depois, foi viabilizado o acesso eletrônico e universal ao conteúdo integral de periódicos internacionais para a comunidade acadêmica de 95 IES, beneficiando mais de 1 milhão de professores e estudantes de graduação e de pós-graduação, com dispêndios de cerca de 16 milhões de dólares. "Quando o Portal chegou ao valor que era gasto em 2002 com as assinaturas em papel, que era de 20 milhões de dólares, ele já oferecia quase 3 mil títulos a 90 instituições. Só aí o ganho já era monumental", falou o professor Abílio Baeta Neves.

O Brasil apresenta-se hoje como um grande consórcio em rede que contempla mais de 180 instituições públicas e privadas, ligadas ao ensino, pesquisa, planejamento e desenvolvimento, para as quais disponibiliza um acervo de mais de 11 mil títulos de periódicos. Em seis anos de existência, completados em novembro de 2006, o Portal de Periódicos da CAPES superou as expectativas dos próprios responsáveis pela sua implantação.

"Sempre faço uma comparação. Se tivéssemos hoje um programa de assinatura em papel de 11 a 12 mil títulos para cem instituiçôes, custaria algo em torno 
de 100 a 150 milhóes de dólares, enquanto o Programa, tal como está, investiu em torno de 30 milhões de dólares em 2006. O custo-benefício é indiscutivel, não apenas em decorrência da economia de escala, antes impossivel de ser alcançada pela participação individualizada das instituições, mas, sobretudo, pela oportunidade de acessar eletronicamente textos completos e bases de dados referenciais, independentemente de localização geográfica e de horário de acesso, constituindo-se num instrumento essencial para o processo de democratização da informação, da educação e da pesquisa nacionais",

disse o professor Abílio Baeta Neves.

\section{A negociação com as editoras}

A escolha das editoras, em um primeiro momento, foi direcionada pela experiência do ProBE/FAPESP. Mais tarde, o processo de seleção das editoras foi objeto de um planejamento minucioso. As dificuldades de negociação foram grandes, principalmente, por se apresentar como cliente uma instituição brasileira. As editoras estavam acostumadas a negociar com os países desenvolvidos, como Estados Unidos, Inglaterra, França e Japão. O Brasil foi o precursor desse tipo de iniciativa na América Latina, surpreendendo de tal forma as editoras, que estas chegaram a mandar representantes ao país para certificarem-se da existência da CAPES, segundo o então presidente.

Em relação aos títulos a serem adquiridos, havia tanto aqueles que já estavam disponíveis no formato eletrônico quanto os que só com o tempo se transformaram em periódicos on-line. Publicaçóes como Science e Nature eram de negociação difícil e de valor muito elevado. Quando as editoras foram percebendo que o Portal de Periódicos formava um consórcio, a relação foise modificando e sendo facilitada.

No início, houve uma tendência de se privilegiarem as áreas biomédicas e exatas, por serem as que concentram maior número de pesquisas. Em 2001, a estratégia de aquisição foi mais dirigida para o campo das engenharias. A negociação com o Institute of Electrical and Electronic Engineers (IEEE) foi difícil porque a instituição não se interessava em disponibilizar material 
nesse modelo, uma vez que privilegiava as bases de dados de patentes junto a clientes privados. O nível de exigência contratual foi tamanho que, quando finalmente passou a integrar o Portal, seu acesso foi limitado a instituições com programas de pós-graduação e pesquisa nas áreas de engenharia elétrica e eletrônica, telecomunicações, ciência da computação, tecnologia da informação e física (CAPES, 2006b). Porém, como se tratava de uma instituição relevante pela qualidade das revistas que disponibiliza, a CAPES aceitou as imposições.

A seleção de periódicos era feita com o intuito de conquistar novos adeptos e de mobilizar a comunidade científica brasileira no sentido de adquirir mais credibilidade. De acordo com o professor Abílio Baeta Neves,

"no inicio, a escolh a das editoras foi limitada pela oferta, pelos recursos e pela necessidade de causar um certo impacto. Se fizéssemos uma escolha muito sofisticada, o sistema poderia ficar muito dirigido e as instituiçôes de ensino e pesquisa não reconheceriam uma tendência positiva".

As negociações, principalmente nas áreas biomédicas, às vezes, davam certo, mas, outras vezes, os títulos eram muito caros e o contrato se tornava inviável.

Também a área de humanas recebeu atenção especial, tendo-se em conta as críticas de que a produção desse campo do conhecimento não está baseada em artigos de revista, mas em livros. Por essa razão, foi incorporada ao Portal a Sage, uma importante editora de livros e revistas para a área, apesar de, na época, não ter ainda um número expressivo de publicações eletrônicas. $\mathrm{Na}$ quele período, também foram integradas ao consórcio editoras especializadas em psicologia, com um grande pacote de revistas.

O fato de o Portal de Periódicos centralizar-se na CAPES é uma característica que também contribuiu para o êxito do projeto. Desde o começo, foi sugerido que o Portal ficasse sob responsabilidade de um pool de agências, o que gerou muitos conflitos e discussóes, até que o MEC reconhecesse que a tarefa de disponibilização de informações científicas deveria ser executada pela CAPES. Assim como é responsável pela pós-graduação, caberia a ela também fornecer o suporte informacional. Por outro lado, a equipe não tinha dúvidas de que, se o projeto envolvesse mais de uma agência, não teria 
sido implantado em 2000, uma vez que a multiplicidade de agências dificultaria uma solução rápida. Conforme o professor Abílio Baeta Neves,

"o programa anterior era formado por quatro agências e ficou reduzido a uma. Se a CAPES não tivesse decidido que era papel dela fazer isso, o programa de aquisição de periódicos para bibliotecas universitárias teria acabado na metade dos anos 1990 e as universidades ficariam cada uma por si”.

No período de implantação, entre 2001 e 2002, houve uma rodada de treinamentos organizada pela Editora Elsevier. Foram realizados encontros regionais de apresentação e divulgação do Portal e de treinamento para os responsáveis pelos sistemas de bibliotecas. O sucesso quase instantâneo fez com que outros países se interessassem pelo projeto, que se transformou numa referência, sendo a CAPES convidada a participar diretamente da criação de um portal semelhante na Argentina. No lançamento do portal argentino, no final de 2002, na página principal, foram colocadas as logomarcas da Secretaria de Ciência e Tecnologia do governo da Argentina e da CAPES, como forma de reconhecimento.

\section{Acesso e uso do Portal}

Comparado a outros, o Portal de Periódicos da CAPES é o maior do mundo em capilaridade, perdendo em volume somente para dois portais americanos que reúnem cerca de 15 mil periódicos cada um. No entanto, os portais das instituições norte-americanas - Harvard University e Massachusetts Institute of Technology (MIT) - são de acesso local, enquanto o Portal brasileiro atende todo o país. São beneficiadas mais de 180 instituições entre IFES, unidades de pesquisa federais, estaduais, municipais e particulares, 33 Centros Federais de Educação Tecnológica (CEFETs) vinculados ao MEC, além de órgãos governamentais, como o Ministério da Ciência e Tecnologia (MCT), o Ministério da Agricultura, Pecuária e Abastecimento (MAPA) e a Empresa Brasileira de Pesquisa Agropecuária (EMBRAPA), algumas das quais pagam pelo acesso ao conteúdo. O Portal atende também universidades públicas não-federais que tenham pelo menos um curso de pós-graduação com 
conceito 4 e universidades particulares com pelo menos um curso em nível de pós-graduação com conceito 5 .

O Portal também é revendido a instituições que não atendem aos critérios estabelecidos, mas que desejam garantir o acesso às bases de dados referenciais e aos periódicos em texto completo. É ainda freqüente uma IES privada assinar o Portal e, quando algum de seus cursos de pós-graduação atinge conceito 5, ela passa a ter acesso gratuito. Também é atendido um conjunto de instituiçõos acadêmicas e não-acadêmicas por meio de senhas, como o Instituto Nacional de Metrologia, Normalização e Qualidade Industrial (INMETRO). Vale ressaltar que a distribuição de senhas é limitada pelos critérios de negociação com as editoras.

Outras instituições pagam pelo uso do Portal um valor correspondente ao cobrado pelas editoras, mais um percentual para a administração interna da CAPES.

"Toda vez que ampliamos o Portal com novos clientes, é feita uma nova negociação com as editoras em função do número de docentes, de alunos, de cursos de pós-graduação e de computadores das instituiçôes. As editoras possuem todos esses dados",

disse o professor Jorge Almeida Guimarães. Segundo ele,

"o Portal de Periódicos é um fator de grande orgulho para nós porque, mesmo os nossos alunos, quando estão no exterior, seja nos Estados Unidos, na França ou na Inglaterra, preferem acionar o Portal da CAPES pelo seu computador pessoal a utilizar os recursos locais. Eles acham muito melhor, mais amplo, amigável, e também porque muitas instituiçōes estrangeiras cobram dos alunos e a CAPES lhes oferece acesso gratuito. Ele tem esse caráter extremamente democrático, embora seletivo do ponto de vista de quem tem direito ao acesso".

A comunidade acadêmica e científica brasileira reconhece a relevância da iniciativa, algo que pode ser facilmente constatado pelo crescimento no número de acessos diários, que inicialmente ficava em 9 mil e hoje representa mais de 100 mil, incluindo feriados e finais de semana. Entre as instituiçóes 
com maior número de acessos, destacam-se a USP, a UNICAMP, a UNESP, a UFRGS, a UFRJ e a UFMG. Diante do sucesso em que se transformou o Portal de Periódicos da CAPES, o presidente lamenta o episódio ocorrido durante 2003 e 2004, quando foi desencadeada uma campanha nacional contra o Portal por causa do seu custo. $\mathrm{O}$ argumento, segundo ele, não se sustenta porque o custo de um download não chega a 50 centavos.

A questão do armazenamento desde o início foi motivo de apreensão por parte da comunidade acadêmica e científica. A comunidade exigiu a manutenção de uma coleção em papel como garantia até que o projeto do Portal estivesse consolidado. Elenara de Almeida disse que fazer uma cópia de segurança em papel por área de conhecimento era praticamente impossível, pois a quantidade de material acumulada por ano corresponderia ao acervo da biblioteca central da Universidade de Brasília (UnB). Posteriormente, a exigência da comunidade passou a ser no sentido da manutenção de uma cópia eletrônica da coleção no país. Depois do atentado de 11 de setembro de 2001 às Torres Gêmeas de Nova York, muitas editoras norte-americanas passaram a disponibilizar espelhos da coleção nos Estados Unidos, na Holanda e em países da América Latina.

\section{A continuidade}

Planos de expansão fazem parte dos objetivos da CAPES, visto que estão crescendo os clientes, sejam públicos ou privados, assim como a própria base, que tem um grande crescimento anual. O custo, em 2006, foi de 30 milhões de dólares, incluindo a Coleção CAPES de Humanidades, constituída de 150 mil livros publicados no século XVIII.

"Embora muitas pessoas achem esse valor substancial, e ele é, representa cerca de 10\% do orçamento da CAPES. Custaria ao MEC 20 vezes mais para manter uma biblioteca modesta em cada uma das mais de 90 instituiçôes de ensino superior que se beneficiam. Portanto, nesse sentido, ele não é caro, além de ser extremamente democrático e abrir espaço para as revistas brasileiras",

argumentou o professor Jorge Almeida Guimarães. 
A decisão de fazer um projeto centralizado na CAPES foi adequada para a consolidação do modelo. No entanto, segundo Elenara de Almeida, o Portal adquiriu tanta dimensão, que não deveria mais ser analisado como de responsabilidade exclusiva do MEC. Embora receba atualmente um aporte de 1 milhão de reais do Fundo Setorial de Infra-Estrutura da FINEP, seria preciso buscar novas parcerias com outros ministérios para que o Portal de Periódicos se transformasse em uma ação de governo, evitando ameaça de extinção, como aconteceu em 2003.

Uma das parcerias que está sendo buscada é com a RNP para a preservação do acervo do Portal. A proposta está sendo desenvolvida em duas etapas: a primeira diz respeito a um processo de uniformização dos acessos a partir de uma entrada única, via Portal, para que a CAPES possa fazer um acompanhamento estatístico mais completo e detalhado, uma vez que os dados sobre consultas são repassados pelos editores em formatos e períodos diferentes; a segunda e última fase consiste na criação de cópias de segurança que serão mantidas em dois ou três locais no Brasil. A primeira etapa também visa facilitar o gerenciamento de uso das coleçôes e auxiliar na compra de pacotes ou títulos específicos oferecidos pelas editoras, assim como melhorar seu controle, conforme a coordenadora da CAC, Elenara de Almeida.

Pelo levantamento histórico aqui realizado, percebe-se que o Portal é uma ferramenta que amplia o acesso à informação científica e tecnológica e viabiliza a inserção do país na ciência internacional. Trata-se, portanto, de uma experiência irreversível, que necessita de constante avaliação e aperfeiçoamento, mas exige continuidade.

No entanto, seus efeitos como biblioteca digital voltada à comunicação científica expressa pela literatura periódica e representada nas bases de dados referenciais não foram completamente mensurados ou qualificados. São necessários estudos bibliométricos e cientométricos que avaliem as mudanças e o impacto que esse acesso trouxe à pós-graduação e à ciência brasileira. 


\section{Referências bibliográficas}

CAPES. Relatório gestão - 2001, Brasília, DF, 2002. Disponível em <http:// www.capes.gov.br/capes/portal/conteudo/CAPES_RelatorioGestao_2001.pdf>. Acesso em 19 de agosto de 2006.

INFOCAPES. Boletim Informativo da CAPES, Brasília, v.10, n.4, 2002.

Portal de Periódicos da CAPES. Brasília, DF, 2006a. Disponível em <http:// www.periodicos.capes.gov.br/portugues/index.jsp>. Acesso em 18 de agosto de 2006.

Portal de Periódicos da CAPES. FAQ: respostas para suas perguntas, Brasília, DF, 2006b. Disponível em <http://www.periodicos.capes.gov.br/portugues/ index.jsp>. Acesso em 18 de agosto de 2006.

Rede Nacional de Ensino e Pesquisa. Promovendo uso inovador de redes avançadas no Brasil, 2006. Disponível em <http://www.rnp.br/_arquivo/documentos/ div0124.pdf>. Acesso em 29 de junho de 2006.

ENDEREÇOS PARA CORRESPONDÊNCIA:

Cynthia Harumi Watanabe Correa - cynthiahwc@yahoo.com.br

Rodovia Celso Garcia, Km380, Centro de Educação, Comunicação e Artes - UEL

Londrina, PR 86051-990 / Tel: (43) 3371-4328

Isabel Merlo Crespo - icrespo@pucrs.br

Av. Ipiranga, 6681, Prédio 16, Partenon, Biblioteca Central Irmão José Otão - PUC-RS

Porto Alegre, RS 90619-900 / Tel: (51) 3320-3544

Ida Regina Chitto Stumpf-irstumpf@ufrgs.br

Rua Ramiro Barcelos, 2705, $2^{\circ}$ andar, Departamento de Ciências da Informação - UFRGS, Santana

Porto Alegre, RS 90035-007 / Tel: (51) 3308-5116 R: 5434

Sonia Elisa Caregnato-sonia.caregnato@ufrgs.br

Rua Ramiro Barcelos, 2705, $2^{\circ}$ andar, Departamento de Ciências da Informação - UFRGS, Santana

Porto Alegre, RS 90035-007 / Tel: (51) 3308-5116 